\title{
Scaling Studio-Based Learning Through Social Innovation Networks
}

\author{
Natalia Smirnov, Matthew W. Easterday, and Elizabeth M. Gerber \\ nsmirnov@u.northwestern.edu, easterday@northwestern.edu, egerber@northwestern.edu \\ Northwestern University, Delta Lab, Ford Design Center
}

\begin{abstract}
In this paper, we articulate a model for scaling Studio-Based Learning (SBL) via a Social Innovation Network (SIN) - a distributed community of design studios collaborating to solve social problems. We report findings from a case study of one SIN called Design for America (DFA), using methods of "ethnography of infrastructure" (Star, 1999) that combine interviews, surveys, and analysis of members' communication on various channels to understand the ways SBL can be orchestrated as a distributed learning community. We argue that principled design and use of cyberlearning tools and organizational routines can foster sociability and trust among members and promote routing of resources across the network, thereby alleviating orchestration challenges and infrastructuring a more effective environment for innovation and design learning.
\end{abstract}

Keywords: design, innovation, networks, orchestration, studio-based learning, cyberlearning

\section{Introduction}

To solve society's most pressing crises such as climate change, refugee displacement, and access to healthcare, 21 st century education should prepare social innovators, people who can recombine resources in creative ways in order to tackle complex, ill-structured problems (Trilling \& Fadel, 2009). However, innovation is difficult to learn, as it depends both on acquiring skills of creative problem-solving, and access to a favorable innovation ecosystem-the resources, skills, collaborators and experts who can guide and support social innovation work (Gundry et al, 2011). Learning sciences is well positioned to improve innovation learning through research on project-based learning, distributed cognition, and adaptive expertise (Blumenfeld et al, 1991; Hutchins, 1995; Hatano \& Oura, 2006). Innovation learning on the other hand is a fruitful discipline for exploring the most interesting of learning sciences inquiries: the integration of STEM, arts, and social policy domains within pressing, real-world problems; and the design of learning environments and technologies to support authentic, expert-guided communities of novice innovators.

There is a timely opportunity to design and mobilize cyberlearning tools to support innovation learning through: (a) scaffolding studio-based learning via affordances of computer-mediated technologies; and (b) connecting design studios across institutions to facilitate sharing of resources, interdisciplinary collaboration and knowledge building. In this paper, we describe how the design studio model offers a promising prototype for an online learning community to support innovation, what we call a social innovation network or SIN (Gerber and Easterday, 2015). We develop our proposal through a case study of Design for America (DFA), a network of 29 university-based studios working to create local and social impact through interdisciplinary design. Using an "ethnography of infrastructure" approach (Star, 1999), we analyze the key features of this social innovation network and the ways different practices and technological systems support and constrain accomplishment of its unique learning goals.

\section{Studio-based learning}

The studio model or Studio-Based Learning (SBL) is a promising approach to designing learning environments that can promote both deep disciplinary learning and creativity (Sawyer, 2012). Characterized by open-ended iterative problem solving, expert coaching, and a culture of sharing and critique, the studio model is especially well suited for supporting complex, project-based forms of learning like innovation. While prevalent in creative domains such as art and architecture, and increasingly utilized in novel informal STEM learning environments, the studio model has not been extensively researched in the learning sciences (Sawyer, 2012). Even less attention has been given to the opportunity to use digital and networked tools to scaffold and scale SBL.

While SBL might be organized similarly to and incorporate features of other learning arrangements, such as classroom, apprenticeship, or informal learning (Lave \& Wenger, 1991; Ito et al, 2009), recent ethnographies of studio-based learning (SBL) have found that the studio has a particular set of norms as a community of practice, where students are expected to: (a) iteratively generate and refine design solutions by incorporating peer and instructor feedback; (b) frequently communicate design ideas visually and verbally, and 
(c) collaborate with peers to give and receive help in achieving learning goals (Cennamo et al, 2011). Studio instructors scaffold these activities through assignments that constrain the complexity of problems, coaching novices through expert feedback, and explicitly reminding students of these cultural norms during critiques. Additionally, Sawyer (2012) found that the studio curriculum thrives on project complexity, engaging learners in problems that require multiple and diverse solutions. Working through this complexity requires continuous externalization of students' insights, initial directions, and partial solutions, exposing them to expert and peer feedback. Thus, the SBL model requires a culture of open sharing, capacity for self-regulation, collaboration, and ongoing iteration. These unique practices make the design studio an especially fruitful context for learning social innovation. However, these distributed and collaborative practices are difficult to scale, because they depend on a complex orchestration of diverse resources and stakeholders, in the context of uncertain and ambiguous problems.

\section{Social innovation networks}

Online learning communities are increasingly being used to increase access to resources, solve orchestration challenges and help make classroom learning more authentically aligned to real-world contexts (Bruckman, 2006). But different online platforms afford different social and learning interactions. Online learning communities should reflect the goals and organizational structures of prototypical learning communities, whether that prototype is a classroom, a tailor apprenticeship, or a neighborhood samba school (Bruckman, 2006). Our goal is to create a widely adopted cyberlearning environment that will support innovation. To that effect, we have been developing the Loft (http://loft.io)-an authentic online learning community based on the studio model. This platform enables learners and instructors to share progress, exchange feedback, collaborate with each other on complex real-world problems, and develop transferrable skills by participating in scaffolded design challenges. While cyberlearning tools can enhance innovation learning within a single studio context by providing a system for project documentation and resource exchange, internet technology can also enable us to take the affordances of studiobased learning further, by connecting people, resources, ideas, and feedback exchange across studios. Thus, we are also developing a new genre of a design learning community that is dependent on radical and distributed connectivity. We call this new genre a social innovation network (SIN).

We define a social innovation network (SIN) as a technologically connected, distributed community of design studios working collaboratively to solve social problems and share design resources. A social innovation network echoes the vision of a collaboratory, developed in the 1950s by William Wulf of National Science Foundation. Enabled by networked technology, a collaboratory is "a center without walls, in which the nation's researchers can perform their research without regard to geographical location-interacting with colleagues, accessing instrumentation, sharing data and computational resource, and accessing information in digital libraries" (Wulf, 1993). In the case of a SIN, the network-enabled collaboration supports the design of social innovations instead of scientific research.

In this paper, we study a specific SIN called Design for America (DFA). DFA is a network of extracurricular studios at 29 universities that brings together interdisciplinary teams of students, faculty, professionals, and alumni to solve real world problems through human centered design. Universities host oncampus DFA studios where student teams work on innovation projects throughout the academic year, by following a systematic design process provided in a downloadable DFA Process Guide and detailed on the Loft platform through interactive challenges. University students who choose to participate in a DFA studio form project teams with other studio members, identify challenges affecting their local community, such as reducing hospitalacquired infections or reducing water waste in cafeterias, and work over the course of a year to understand user needs, ideate, prototype, test, and implement solutions. In the process, they partner with community organizations, and receive coaching from local design professionals, support from more experienced DFA mentors at the national office (5 full-time DFA staff), and regular feedback from their peers on campus. Because the studios are selforganized and participation of all the stakeholders is voluntary, the organization of the studios is very loosely structured and adapted to meet the culture and rhythm of the respective college campuses. Rather than mandating a particular set of administrative roles and activities, the five full time DFA national staff provide ongoing support to the different studios' emerging challenges and needs through bi-annual campus visits, regular video conference check-ins, email newsletters with tips and suggestions, and a yearly Leadership Studio that brings together studio leaders from all the DFA campuses for one week to learn the design process, share best practices, and troubleshoot common studio problems. Since this community is distributed across the entire country, DFA leaders and members heavily rely on digital communication tools, including Google docs, Slack and the Loft.io platform, to 
connect and collaborate with each other and support studio-based learning. Our study of DFA was designed to answer the following questions:

1. How does DFA currently orchestrate distributed Studio-Based Learning (SBL)?

2. What are the affordances and constraints of existing communication and collaboration tools and practices DFA leaders and members use for realizing the goals of the distributed SBL community?

3. Which principles might we use to better design socio-technical systems (jointly optimized organizational routines and cyberlearning tools) to facilitate learning and social innovation in this type of learning organization?

\section{Methods}

This inquiry into the communication and collaboration practices of DFA members and leaders followed an "ethnography of infrastructure" (Star, 1999) approach-examination of the "boring things" that reveal the background workings and assumptions of a complex socio-technical system. We followed this approach because we noticed that even though we had designed and implemented a platform specifically for Studio-Based Learning (e.g. the Loft), DFA members were using other tools in addition (e.g. Facebook, GroupMe, Google Docs, etc) to connect and collaborate with each other, both within and across studios. Thus, the existing cyberlearning platform was not adequately meeting the needs of members at the network level. Members and leaders of DFA repeatedly expressed desire for more resource sharing and coaching specifically at this scale. We wanted to understand why DFA members chose to use certain communication and collaboration tools, how they used them (e.g. via what routines) and what those tools afford and constrain in terms of learning and collaboration. Studying both tools and routines helps us deepen our understanding of this learning community and generate design principles for developing new tools and routines to better support the goals of this system. We believe that while specific technological designs can afford particular practices and interactions, technologies themselves do not determine social behaviors. Rather, social behaviors are mediated by users' mental models, circumstances, goals and tactics (Geels, 2004, Fischer, 2007). As such, we emphasize the need for joint optimization of both organizational routines and technologies, and for attending to continuous emergence and adaptation mechanisms within a sociotechnical system (Trist, 1981; Bruckman, 2004).

\section{Data collection and analysis}

We studied the network-level practices, strategies, and goals of DFA in three ways. First, we collected and analyzed communication and collaboration practices of network members at the network level, or across studios. For example, we collected posts on DFA's Student Network Facebook Page, cross-studio discussions on Loft, and other platforms and channels (GroupMe, Text, GoogleDocs). Second, we conducted interviews with network leaders about their mental model of the DFA network and its goals, and the tools and routines they use to support DFA studios to support their project teams and connect to each other. Third, we surveyed 72 studio leaders about what supports are needed for managing their studios and the current communication and collaboration tools in use by studio members.

This data collection was iterative, with each phase of collection and analysis informing the next round of questions. For example, analysis of DFA social media practices prompted us to consider the network leaders' decision to setup and use particular tools and not others. We were interested in this group in particular because they are primarily responsible for orchestrating learning at the network level, whereas studio leads and faculty coaches support individual studio learning. In interviews, we first asked the five DFA leaders (4 full-time fellows and 1 administrator) to draw a "map of the DFA community" while talking aloud about the different actors they were illustrating. This drawing served as a useful representation for the rest of the interview, providing a reference for the multiple stakeholders of the network and illustrating the ways different digital tools were used to communicate and collaborate by certain members of the DFA community and not others. We analyzed the interview transcripts using a grounded theory approach, first open coding transcripts to generate emerging themes, then specifying a set of descriptive codes, and applying these codes systematically to the entire data set (Charmaz, 2014). The coding was performed by the first author and discussed and refined in weekly research meetings with the rest of the research team. This analysis revealed that individual DFA leaders' communication practices were idiosyncratic and relied primarily on anecdotal evidence rather than analytics or extensive understanding of member needs. This finding prompted us to conduct need-finding interviews and develop a survey to understand the needs of DFA student members and the digital tools they already use to communicate and collaborate with each other. The survey was completed by 72 studio leaders at the annual all-network training conference. We 
analyzed the digital tool use and needs of DFA members, comparing them with our findings from DFA staff interviews. Finally, we continued to collect examples of cross-studio communication on various platforms, triangulating our emerging thematic categories with new evidence (Yin 2013; Stake, 1995). As we advanced in our analysis, we compared empirical findings to existing theoretical constructs (Snow, Morrill \& Anderson, 2003), and created explanatory matrices and networks (Miles, Huberman, Saldaña, 2013) to model relationships between various parts of the system (See tables 1 and 2).

\section{Findings}

\section{How does the Studio model scale?}

Studio-based learning (SBL) is characterized by a set of norms and practices including project complexity, public critiques, and expert coaching (Sawyer, 2012; Cennamo, 2011). These norms are realized in the DFA studio-level organizational practices and afforded by the cyberlearning tools, including the Loft (Easterday et al, 2015; Rees Lewis et al, 2015). In this study, we have zoomed out to examine the learning infrastructures at the network level that allow DFA to realize SBL model across institutions to support studios to carry out design and innovation work (see Table 1). In the table below, we present a concise summary of this 3-level dynamic, from the SBL theoretical model to studio practices to network organization. The two columns on the right present the findings specific to this study. The DFA goals and practices column presents examples of network-building activities from our ethnography, while the rightmost column summarizes organizational needs to inform future cyberlearning tools and routines. These needs combine suggestions and wishes of DFA network leaders and members, articulated in interviews and surveys and ideas generated by the research team through the analysis of the data. Some potential ideas for adapting existing practices and creating new tools and routines are listed in parenthesis.

Table 1: Studio-Based Learning (SBL) Model at the Studio and Network Levels

\begin{tabular}{|c|c|c|c|c|c|}
\hline $\begin{array}{l}\text { Features of } \\
\text { the Learning } \\
\text { Environment }\end{array}$ & $\begin{array}{l}\text { Studio- } \\
\text { Based } \\
\text { Learning } \\
\text { (SBL) }\end{array}$ & $\begin{array}{c}\text { How DFA } \\
\text { orchestrates SBL } \\
\text { within studios }\end{array}$ & $\begin{array}{c}\text { Tools and } \\
\text { routines to } \\
\text { support } \mathrm{SBL} \\
\text { within studios }\end{array}$ & $\begin{array}{l}\text { DFA goals and practices } \\
\text { to orchestrate SBL } \\
\text { across studios }\end{array}$ & $\begin{array}{c}\text { Organizational needs } \\
\text { for tools \& routines to } \\
\text { support distributed } \\
\text { SBL }\end{array}$ \\
\hline $\begin{array}{l}\text { type of } \\
\text { problem } \\
\text { solved }\end{array}$ & $\begin{array}{l}\text { Students } \\
\text { work on } \\
\text { complex } \\
\text { real-world } \\
\text { problems }\end{array}$ & $\begin{array}{l}\text { DFA Teams } \\
\text { partner with local } \\
\text { community } \\
\text { organizations to } \\
\text { work on real- } \\
\text { world dilemmas in } \\
\text { healthcare, } \\
\text { education, etc. }\end{array}$ & $\begin{array}{l}\text { Tools to manage } \\
\text { project complexity } \\
\text { (Scoping Wheel, } \\
\text { Design Canvas) }\end{array}$ & $\begin{array}{l}\text { Studio leads confront } \\
\text { many real-world } \\
\text { challenges, such as } \\
\text { member recruitment, } \\
\text { leadership organization, } \\
\text { managing relationships } \\
\text { with partners, working } \\
\text { with coaches, etc. }\end{array}$ & $\begin{array}{l}\text { Help studio leads } \\
\text { anticipate, externalize } \\
\text { and respond to common } \\
\text { studio challenges } \\
\text { (Studio guides, FAQs, } \\
\text { training, mentoring) }\end{array}$ \\
\hline $\begin{array}{c}\text { support } \\
\text { provided by } \\
\text { instructor(s) } \\
\text { or system }\end{array}$ & $\begin{array}{l}\text { Scaffolding } \\
\text { through } \\
\text { constrained } \\
\text { assignments, } \\
\text { expert } \\
\text { modeling } \\
\text { and } \\
\text { coaching, } \\
\text { and prompts }\end{array}$ & $\begin{array}{l}\text { Studio leads guide } \\
\text { teams through } \\
\text { phases of the } \\
\text { design process, } \\
\text { using DFA process } \\
\text { guide and LOFT.io } \\
\text { tutorials }\end{array}$ & $\begin{array}{l}\text { Design Process } \\
\text { Scaffolds (Guides, } \\
\text { Design } \\
\text { Challenges, } \\
\text { Scoping Wheel, } \\
\text { Coaching Stands, } \\
\text { regular mentoring } \\
\text { calls) }\end{array}$ & $\begin{array}{l}\text { National staff support } \\
\text { studio leads to facilitate } \\
\text { learning within their } \\
\text { studios (e.g. recruitment, } \\
\text { critiques) but must } \\
\text { manage: (a) varied studio } \\
\text { calendars; (b) busy } \\
\text { student schedules; (c) } \\
\text { unreliable communication } \\
\text { practices; and (d) limited } \\
\text { time of } 5 \text { staff }\end{array}$ & $\begin{array}{l}\text { Just-in-time reminders } \\
\text { and prompts for how to } \\
\text { facilitate a studio-wide } \\
\text { activity (email } \\
\text { newsletters; social } \\
\text { media reminders; } \\
\text { Group Calls) }\end{array}$ \\
\hline $\begin{array}{c}\text { demands on } \\
\text { learners }\end{array}$ & \begin{tabular}{|l|} 
Students \\
self-regulate \\
goal-setting \\
and progress \\
management
\end{tabular} & $\begin{array}{l}\text { Project Teams } \\
\text { consistently meet } \\
\text { independently to } \\
\text { work on projects }\end{array}$ & $\begin{array}{l}\text { Tools and routines } \\
\text { to support goal } \\
\text { setting and } \\
\text { planning (to-do } \\
\text { lists, Workbench, } \\
\text { Calendar) }\end{array}$ & $\begin{array}{l}\text { Studios must adapt } \\
\text { process and governance to } \\
\text { their own campus } \\
\text { structure and culture; } \\
\text { studio leads might have } \\
\text { little to no experience } \\
\text { leading an organization }\end{array}$ & $\begin{array}{l}\text { Support studio goal } \\
\text { planning and flexible } \\
\text { adaptation to campus } \\
\text { culture. (e.g. Group } \\
\text { Calls, Campus Visits) }\end{array}$ \\
\hline organizational & Regular & Studio crits allow & Tools and routines & Annual DFA Leadership & Make resources and \\
\hline
\end{tabular}




\begin{tabular}{|c|c|c|c|c|c|}
\hline routines & $\begin{array}{l}\text { exhibition/ } \\
\text { visualization } \\
\text { of progress } \\
\text { \& problems } \\
\text { (Critiques or } \\
\text { Crits) }\end{array}$ & $\begin{array}{l}\text { teams to share } \\
\text { progress and } \\
\text { receive feedback }\end{array}$ & $\begin{array}{l}\text { to support progress } \\
\text { sharing and } \\
\text { feedback with } \\
\text { coaches and } \\
\text { mentors (Virtual } \\
\text { Stands, feedback } \\
\text { features on Loft) }\end{array}$ & $\begin{array}{l}\text { Studio provides } \\
\text { opportunity for studio } \\
\text { leads to share best studio } \\
\text { management practices } \\
\text { and tools }\end{array}$ & $\begin{array}{l}\text { progress visible across } \\
\text { studios more regularly } \\
\text { (Cross-studio meetups; } \\
\text { email updates; Tool } \\
\text { Expos; Group Calls; } \\
\text { Facebook/Twitter } \\
\text { Updates; Studio } \\
\text { Dashboard) }\end{array}$ \\
\hline $\begin{array}{l}\text { role of peers } \\
\text { and mentors }\end{array}$ & $\begin{array}{l}\text { Reliance on } \\
\text { peer } \\
\text { collaboration } \\
\text { and expert } \\
\text { mentoring to } \\
\text { achieve } \\
\text { learning } \\
\text { goals }\end{array}$ & $\begin{array}{l}\text { DFA projects are } \\
\text { collaborative; } \\
\text { teams are } \\
\text { supported by } \\
\text { coaches and } \\
\text { faculty advisors } \\
\text { via critiques and } \\
\text { stands }\end{array}$ & $\begin{array}{l}\text { Tools and routines } \\
\text { to foster peer } \\
\text { support and help- } \\
\text { seeking (Cheers, } \\
\text { Feedback } \\
\text { Routines, Stands) }\end{array}$ & $\begin{array}{l}\text { National staff want DFA } \\
\text { members to connect to } \\
\text { each other directly to } \\
\text { share resources and } \\
\text { provide help and activate } \\
\text { the power of the DFA } \\
\text { alumni network for } \\
\text { mentorship }\end{array}$ & $\begin{array}{l}\text { Facilitate help seeking, } \\
\text { giving and information } \\
\text { routing across studios } \\
\text { based on similarities } \\
\text { (Help Forum, Tagging, } \\
\text { Cross-studio meetups, } \\
\text { Networking activities, } \\
\text { Recommender system); } \\
\text { Attract and retain } \\
\text { professional mentors }\end{array}$ \\
\hline $\begin{array}{l}\text { timescale of } \\
\text { work }\end{array}$ & $\begin{array}{l}\text { Cycles of } \\
\text { Ongoing } \\
\text { Iteration }\end{array}$ & $\begin{array}{l}\text { DFA are teams } \\
\text { encouraged to } \\
\text { continue working } \\
\text { on their projects } \\
\text { after first year }\end{array}$ & $\begin{array}{l}\text { Non-linear tools } \\
\text { for authoring and } \\
\text { archiving multiple } \\
\text { solution prototypes } \\
\text { (Challenges, } \\
\text { Feedback) }\end{array}$ & $\begin{array}{l}\text { Network practices change } \\
\text { as network grows; } \\
\text { Members join studios on } \\
\text { a rolling basis, require } \\
\text { onboarding. } \\
\text { Studio leadership turns } \\
\text { over as students graduate. }\end{array}$ & $\begin{array}{l}\text { Crowdsource } \\
\text { curriculum authoring } \\
\text { and revision, preserve } \\
\text { traditions and train new } \\
\text { leadership (Wiki, } \\
\text { Leadership Ladder) }\end{array}$ \\
\hline
\end{tabular}

DFA orchestrates Studio-Based Learning - guided, collaborative, iterative, real-world problem-solving - both within and across studios (Table 1). Running a DFA studio is its own form of a complex, real-world challenge that requires ongoing problem refining, help-seeking, iteration, and just-in-time learning. Just like in an SBL context, there is no one right answer to the problem of "how to run a studio" and expertise is distributed across the community of other novice learners and volunteer coaches. To support this SBL network, the organizational leaders need to "scale"-replicate and adapt-the practices of SBL instruction to 29 universities, 120+ projects and $900+$ active student members. The limited capacity of 5 full-time staff to effectively support all these stakeholders and their needs presents significant orchestration challenges. From our interviews with network and studio leaders, we found that the primary goals and needs of this SIN are to connect network stakeholders with each other to promote resource sharing, help-seeking and giving, and orchestrate social and pedagogical support for the studios and teams to follow the design process. Leaders and members of the network adapted various information and communication technologies (ICTs) to orchestrate resource sharing and collaboration across studios. In our interviews, DFA national staff mentioned 37 ICTs that they either currently used or considered using for DFA activities, including social media, video conferencing, project management and collaboration tools. In our survey of DFA studio leaders, students mentioned 18 separate digital platforms that they use on a daily basis. Below we analyze the affordances and constraints of the most frequently used ICTs for supporting this Social Innovation Network.

\section{How do ICTs support and constrain SINs?}

To illustrate the use of ICTs to orchestrate distributed SBL, consider the following vignette of an hour-long video call on Adobe Connect with leaders from the 29 DFA studios across the country. Three group calls happened at the same time, with several studios per group, facilitated by 1 national staff member each. Two weeks prior, studio leads received an email asking them to fill out a Google Form and list their studio's upcoming events and current challenges. The results were organized by the DFA national staff in a Google Spreadsheet, based on similarity of the goals, the kinds of help each studio needs, variability of experience, and "diversity" of studiosone of the goals of this call is make studio leads talk with leaders from different universities than they did last month. 10 participants from 3 different time zones joined one of the video calls. 3 of these attendees had trouble with their microphones, so they had to type in the chat window instead of talking. One student came in late; two participants had to leave early to go to other meetings. The students introduced themselves and discussed how each of their studios was dealing with various types of design feedback - from studio peers, professional mentors, 
and target users. Studio leaders shared exemplary practices (e.g. "a workshop on presenting your work" or "we do a weekly pin-up session with professionals"), others surfaced concerns ("are we losing sight of users?"). The DFA staff member facilitated the conversation, took notes in a Google Doc, and tried to acknowledge and respond to the contributions from students typing in the chat while others spoke out loud. With less than 10 minutes left, the facilitator asked each person to name their takeaways and reflect on how the call went. Participants were surprised by the diversity of practices across campuses and wished to know more about each studio's different projects. Then the facilitator said "let's take a screenshot!", counted "1-2-3" and pressed a several keys to capture a still of her computer screen. As the call ended, the DFA leader sighed, "I'm always so tired after these!" and then immediately, "I have to tweet this now."

The example above captures only some of the tools DFA members currently use to orchestrate distributed, student-led studio-based learning. One of the most prominently used tools in this community is Facebook Groups: there is a Facebook Group for each DFA studio, one just for studio leads, one for the entire network, one for alumni, and a group for DFA-ers interested in traveling together. Facebook was also mentioned as the most widely used tool in the DFA member survey. The group messaging app GroupMe is used by local team members to manage their collaboration and by studio leads to keep in touch after annual and regional meetups. A few studios have recently adopted the platform Slack as a way to manage communication between teams and mentors within a studio. This combination of ICTs is tactical-an ad-hoc assemblage of available and familiar resources to achieve emerging goals (De Certeau, 1984). While DFA network uses ICTs in ways that are creative, adaptive and practical, our study also helps to highlight the limitations of these tools, as they have not been designed explicitly or strategically to support distributed studio-based learning. For example, DFA members complained that the Facebook feed doesn't allow easy searching, archiving or re-organizing of information that could be potentially useful to future studio leaders or network members. Similarly, Google Docs lack standards for organization and archiving. As one of our informants said, "My personal hell is being lost in someone else's GoogleDoc." Despite its capacity to facilitate virtual face-to-face meetings, much of the time during teleconferences on Adobe Connect may be spent managing internet connections or software issues. In the table 2 below, we summarize the features and qualities of ICTs most commonly used by DFA members that were addressed as salient in our interviews and observations.

Table 2: Features and Affordances of ICTs for supporting distributed SBL

\begin{tabular}{|c|c|c|c|c|c|c|c|c|c|}
\hline & Features and affordances of ICTs & $\begin{array}{c}\text { Facebook } \\
\text { Groups }\end{array}$ & $\begin{array}{c}\text { Group } \\
\mathrm{Me}\end{array}$ & $\begin{array}{c}\text { Google } \\
\text { Docs }\end{array}$ & $\begin{array}{l}\text { Google } \\
\text { Hangout }\end{array}$ & $\begin{array}{c}\text { Adobe } \\
\text { Connect }\end{array}$ & Email & Loft & Slack \\
\hline \multirow{2}{*}{$\begin{array}{c}\text { Ease of } \\
\text { onboarding }\end{array}$} & Familiar to participants & $\checkmark$ & $\checkmark$ & $\checkmark$ & $\checkmark$ & & $\checkmark$ & & \\
\hline & Mobile App & $\checkmark$ & $\checkmark$ & & $\checkmark$ & & $\checkmark$ & & $\checkmark$ \\
\hline \multirow{3}{*}{$\begin{array}{c}\text { Intra-team } \\
\text { collaboration }\end{array}$} & Collaborative Authoring / Production & & & $\checkmark$ & & & & $\checkmark$ & \\
\hline & Project-Management Tools & & & & & & & $\checkmark$ & \\
\hline & Shared/cloud storage of documents & $\checkmark$ & & $\checkmark$ & & & & $\checkmark$ & $\checkmark$ \\
\hline \multirow{4}{*}{$\begin{array}{c}\text { Network } \\
\text { wide } \\
\text { resource sharing }\end{array}$} & Many-to-many conversation & $\checkmark$ & $\checkmark$ & & $\checkmark$ & $\checkmark$ & & & $\checkmark$ \\
\hline & User- and category- tagging, sharing & $\checkmark$ & & & & & & & $\checkmark$ \\
\hline & Feedback, voting, polling, annotation & $\checkmark$ & & $\checkmark$ & & & & $\checkmark$ & \\
\hline & Alerts, notifications & $\checkmark$ & $\checkmark$ & & & & $\checkmark$ & $\checkmark$ & $\checkmark$ \\
\hline \multirow{3}{*}{$\begin{array}{c}\text { Affective } \\
\text { Infrastructure }\end{array}$} & Emojis, reactions, photo posting & $\checkmark$ & & & $\checkmark$ & & & & $\checkmark$ \\
\hline & Virtual Face2Face (video/audio) & & & & $\checkmark$ & $\checkmark$ & & & \\
\hline & "Less Formal" & $\checkmark$ & $\checkmark$ & & $\checkmark$ & & & & \\
\hline \multirow{2}{*}{$\begin{array}{c}\text { Organizational } \\
\text { Strategy }\end{array}$} & "More Professional" & & & & & $\checkmark$ & $\checkmark$ & $\checkmark$ & $\checkmark$ \\
\hline & Analytics & $\checkmark$ & & & & & $\checkmark$ & & \\
\hline
\end{tabular}




\begin{tabular}{|l|l|l|l|l|l|l|l|l|l|}
\hline & Standardized archiving & & & & & & & $\checkmark$ & \\
\hline
\end{tabular}

We organized ICT features into 5 major categories: (1) ease of onboarding, (2) intra-team collaboration features, (3) inter-team/network-wide information routing and resource sharing, (4) affective infrastructure, and (5) functions that support organizational strategy rather than solve an immediate problem. As this analysis demonstrates, there is no one perfect platform that meets all of the needs of this community. While Facebook emerges as extremely versatile with regard to several variables (familiarity, collaborative features, affective expression and so on), it lacks project management tools to facilitate teamwork or archiving tools to organize useful information developed in discussions for future use. In addition, because DFA is both extra-curricular and proto-professional-students volunteer to join DFA and lead studios, but often view it as a stepping stone to potential design jobs-it must balance being fun and social, while also supporting professional skill development. Part of our research project is to articulate design principles for developing and assembling ICTs to support innovation learning. Intentionally designed cyberlearning tools can help to capitalize on affordances of existing technologies while enabling more productive collaboration and resource sharing among SIN members. Next, we highlight two key principles for designing cyberlearning tools to support SBL at the distributed network level: affective infrastructure and information routing.

\section{Design principles for socio-technical systems to support SINs}

\section{Affective infrastructure}

Across the different preferred modes of collaboration and communication, network members placed high importance on affective modes of expression (e.g. emojis, pictures, reactions, and video calls). Posting silly photos and videos and using emojis in their conversations helped them build more sociability and trust with their peers, which facilitated other kinds of knowledge building and design resource sharing. The affective infrastructure is thus a critical feature of the SBL environment. As designers, we must attend to the ways the learning environment (or technology) is affectively experienced-as fun or formal, as exciting or boring, institutional or personal-and specific infrastructural features that promote trust and sociability, which in turn foster resource sharing and helpseeking.

\section{Information routing}

In a distributed SBL community, or SIN, it is impossible for any member of the network to attend to all the information exchanged between various parts of the network and consider its usefulness for his/her own purposes. Information routing (Resnick, 2001) is a form of socially-distributed filtering to manage this problem. For example, when resources or opportunities were posted on the DFA Facebook page, members used the Facebook user tagging feature to alert other network members and bring them into the conversation. DFA staff intentionally organized group calls to facilitate information routing between more and less experienced studio leaders. As designers, we must consider features and routines for information routing, such as the ability to tag other users to alert them of a relevant discussion, or automatic targeted notifications based on user-specified interests or roles.

\section{Discussion}

Learning Sciences has a long tradition of designing cyberlearning tools to support project- and inquiry-based learning (Edelson, Gordin, Pea, 1999). Our case study of a distributed studio-based learning community extends this tradition by focusing on a new disciplinary domain (design learning), articulating a new genre of a learning infrastructure (social innovation network), and proposing two design principles for building socio-technical systems that enhance SINs. Specifically, we have argued that attending to affective infrastructure and information routing will facilitate the creation of communication channels and resource sharing across a distributed network of studios, thus supporting innovation learning and design. These considerations are likely missing from previous ethnographies of SBL because the small scale and face-to-face interaction of typical studio classes allow affective infrastructure and information routing to be taken for granted (Colyvas \& Powell, 2006).

\section{References}

Blumenfeld, P. C., Soloway, E., Marx, R. W., Krajcik, J. S., Guzdial, M., \& Palincsar, A. (1991). Motivating project-based learning: Sustaining the doing, supporting the learning. Educational Psychologist, 26(34), 369-398. 
Bruckman, A. (2004). Co-evolution of technological design and pedagogy in an online learning community. Designing for Virtual Communities in the Service of Learning, 239-255

Bruckman, A. (2006). Learning in online communities. In Cambridge handbook of learning sciences.

Cennamo, K., Brandt, C., Scott, B., Douglas, S., McGrath, M., Reimer, Y., \& Vernon, M. (2011). Managing the complexity of design problems through studio-based learning. Interdisciplinary Journal of Problembased Learning, 5(2), 5.

Charmaz, K. (2014). Constructing Grounded Theory. Sage. Colyvas, J. A., \& Powell, W. W. (2006). Roads to institutionalization: The remaking of boundaries between public and private science. Research in organizational behavior, 27, 305-353.

De Certeau, M. (1984). The practice of everyday life. Berkeley: University of California Press.

Easterday, M., Lewis, D. R., \& Gerber, E. (2013). Formative feedback in Digital Lofts: Learning environments for real world innovation. In AIED Workshops.

Easterday, M. W., Rees Lewis, D., \& Gerber, E. M. (2015). Crowdsourcing critique. In CSCL crowd 2015, a workshop at the 2015 International Conference on Computer Supported Collaborative Learning, June 7, Gothenburg, Sweden.

Edelson, D. C., Gordin, D. N., \& Pea, R. D. (1999). Addressing the challenges of inquiry-based learning through technology and curriculum design. Journal of the learning sciences, 8(3-4), 391-450.

Fischer, G. (2007). Designing socio-technical environments in support of meta-design and social creativity. In Proceedings of the 8th international conference on computer supported collaborative learning.

Geels, F. W. (2004). From sectoral systems of innovation to socio-technical systems: Insights about dynamics and change from sociology and institutional theory. Research Policy, 33(6), 897-920.

Gerber, E., \& Easterday, M. (2015). Social innovation networks: Models, outcomes, and challenges. In Proceedings of the MDWIX.

Gundry, L. K., Kickul, J. R., Griffiths, M. D., \& Bacq, S. C. (2011). Entrepreneurial Bricolage and Innovation Ecology: Precursors to Social Innovation? Frontiers of Entrepreneurship Research, 31(19), 3.

Hatano, G., \& Oura, Y. (2003). Commentary: Reconceptualizing school learning using insight from expertise research. Educational Researcher, 32(8), 26-29.

Hutchins, E. (1995). How a cockpit remembers its speeds. Cognitive science, 19(3), 265-288.

Ito, M., Antin, J., Finn, M., Law, A., Manion, A., Mitnick, S., ... \& Horst, H. A. (2009). Hanging out, messing around, and geeking out: Kids living and learning with new media. MIT press.

Miles, M. B., Huberman, A. M., \& Saldaña, J. (2013). Qualitative data analysis: A methods sourcebook. SAGE Publications, Incorporated.

Rees Lewis, D., Easterday, M., Gerber, E. M., (2015). Supporting Project Scoping: The Scoping Wheel. In Proceedings of the Harvey Mudd Design Workshop IX. May 28-30, Claremont, CA, US.

Resnick, P. (2001). Beyond bowling together: Sociotechnical capital. HCI in the New Millennium, 77, $247-272$.

Snow, D. A., Morrill, C., \& Anderson, L. (2003). Elaborating analytic ethnography: Linking fieldwork and theory. Ethnography, 4(2), 181-200.

Stake, R. E. (1995). The art of case study research. Sage.

Star, S. L. (1999). The ethnography of infrastructure. American Behavioral Scientist, 43(3), 377-391.

Trilling, B. \& Fadel, C. (2009). 21 st century skills: learning for life in our times. Jossey-Bass: San Francisco.

Trist, E. (1981). The evolution of socio-technical systems. Occasional paper, 2, 1981.

Wulf, W. A. (1993). The collaboratory opportunity. Science, 261(5123), 854-855.

Yin, R. K. (2013). Case study research: Design and methods. Sage publications

\section{Acknowledgments}

The authors thank DFA leaders and members who participated in interviews and surveys analyzed for this study. Thanks to Daniel Rees Lewis, Rob Calvey and Stacy Klingbeil for help with data collection, Alex Sher and Andre Mohring for help on data transcription and analysis, and members of Northwestern Delta Lab for ongoing feedback, moral support and inspiration. This work was supported by the National Science Foundation grants IIS $1320693 / 1217225$ and Venture Well. 